\title{
Dynamic properties of wavelength switching in a widely tunable semiconductor laser for optical coherence tomography (Erratum)
}

Rastko Pajković, Daniel Garbi, Kevin Williams, Erwin Bente

Rastko Pajković, Daniel Garbi, Kevin Williams, Erwin Bente, "Dynamic properties of wavelength switching in a widely tunable semiconductor laser for optical coherence tomography (Erratum)," Proc. SPIE 11356, Semiconductor Lasers and Laser Dynamics IX, 113561F (27 July 2020); doi:

$10.1117 / 12.2579913$

SPIE. Event: SPIE Photonics Europe, 2020, Online Only 
Dynamic properties of wavelength switching in a widely tunable semiconductor laser for optical coherence tomography (Erratum)

Rastko Pajković, Daniel Garbi, Kevin Williams, Erwin Bente

Author Affiliations -

Rastko Pajković, ${ }^{1}$ Daniel Garbi, ${ }^{1}$ Kevin Williams, ${ }^{1}$ Erwin Bente ${ }^{1}$

${ }^{1}$ Technische Univ. Eindhoven (Netherlands)

Proceedings Volume 11356, Semiconductor Lasers and Laser Dynamics IX; 113560I

(2020) https://doi.org/10.1117/12.2555620

Event: SPIE Photonics Europe, 2020, Online Only

Event SPIE Photonics Europe 2020 (EPE20), 2020, online

Online Publication Date: 1 April 2020

Eratum Published: 27 J uly 2020

A revised version of this manuscript was published on 27 J uly 2020. Details of the revision are provided in the text that accompanies this Erratum. The original paper has been updated.

1). Figure three was altered from:
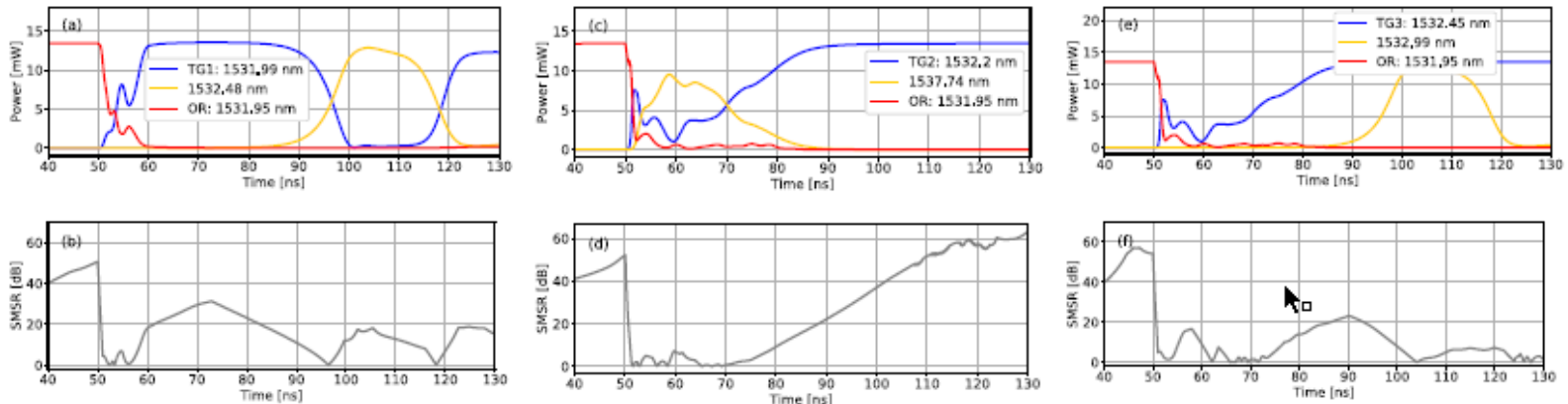

Figure 3 Simulation results for wavelength switching from $1531.95 \mathrm{~nm}$ for 3 different strategies: (a) and (b) switching to a neighboring longitudinal cavity mode $0.04 \mathrm{~nm}$ apart, (c) and (d) switching to the valley of the fine filter $0.25 \mathrm{~nm}$ apart, (e) and (f) switching to the neighboring peak of the fine filter $0.5 \mathrm{~nm}$ apart.

To:
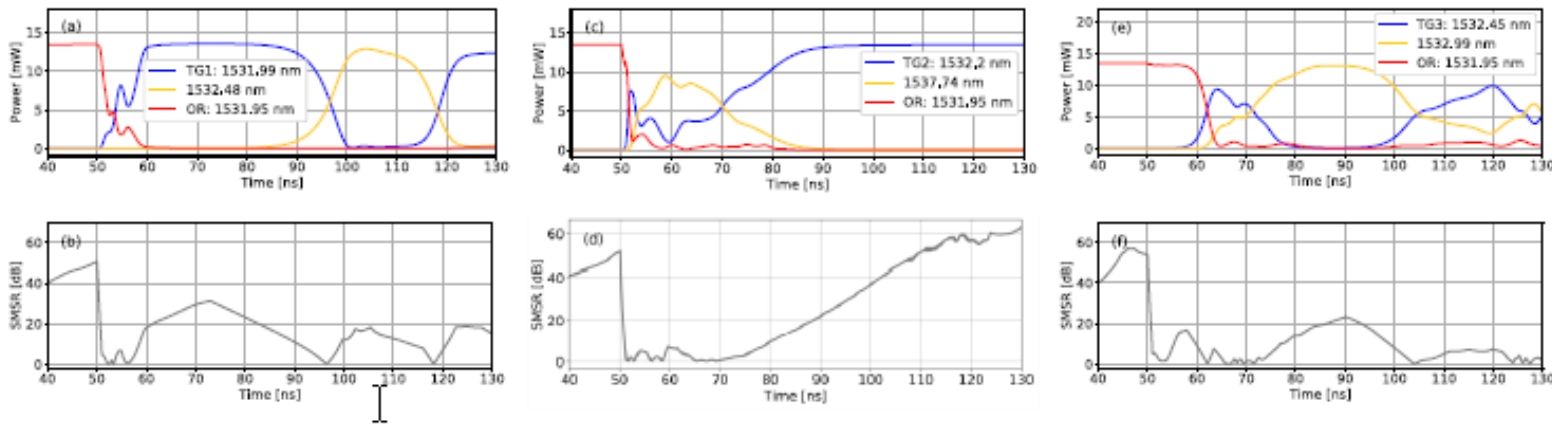

Figure 3 Simulation results for wavelength switching from $1531.95 \mathrm{~nm}$ for 3 different strategies: (a) and (b) switching to a neighboring longitudinal cavity mode $0.04 \mathrm{~nm}$ apart, (c) and (d) switching to the valley of the fine filter $0.25 \mathrm{~nm}$ apart, (e) and (f) switching to the neighboring peak of the fine filter $0.5 \mathrm{~nm}$ apart

2). Figure 1 was shown in the original document twice. It is now shown in the paper only once. 